\title{
Proximidade espacial versus distância social: examinando as articulações entre grupos socialmente distantes em três bairros populares de Salvador, Brasil
}

\author{
Spatial proximity versus social distance: \\ examining the articulations between socially distant \\ groups in three shantytowns of Salvador, Brazil
}

Stephan Treuke [l]

\begin{abstract}
Resumo
Neste artigo, propõe-se indagar se existem maiores oportunidades de integração socioeconômica da população dos bairros populares Calabar, Vale das Pedrinhas e Bate Facho (Salvador, BA), dada sua inserção em uma região habitada pelas classes média e alta. Examinando o efeito-território nas dimensões material, social e simbólica, à base de entrevistas semiestruturadas, destacam-se quatro fatores que caracterizam essas configurações urbanas: as oportunidades empregatícias tendo em vista a demanda dos moradores dos condomínios por serviços pessoais; o acesso segmentado aos serviços urbanos; a evitação social excetuando-se os vínculos empregatícios; a estigmatização territorial. Concluindo, a variabilidade entre os locais concernentes à integração socioeconômica do indivíduo atrela-se à capacidade de os espaços compartilhados viabilizarem trocas mercantilistas e à interferência da criminalidade na organização social do bairro.
\end{abstract}

Palavras-chave: efeito-território; segregação residencial; segmentação social; pobreza urbana; estigmatização territorial.

\begin{abstract}
In this article, we aim to investigate whether the embeddedness of the shantytowns Calabar, Vale das Pedrinhas and Bate Facho (city of Salvador, State of Bahia) in a middle- and upper-class region fosters their populations' socioeconomic integration. Assessing neighborhood effects on the material, social and symbolic dimensions based on semi-structured interviews, we highlight four factors that characterize these urban configurations: employment opportunities arising from the gated community dwellers' demand for personal services; segmented access to urban services; social avoidance, except for employment relationships; and territorial stigmatization. We conclude that the variability found among the places regarding the individual's socioeconomic integration is related to the public spaces' capacity for enabling commercial exchanges and to the impact of criminality on the neighborhoods' social organization.
\end{abstract}

Keywords: Neighborhood effects; residential segregation; social segmentation; urban poverty; territorial stigmatization. 


\section{Introdução}

A abordagem da pobreza urbana e a análise das estruturas de segregação residencial representam dois campos de pesquisa estreitamente interligados dentro da sociologia urbana estadunidense que foram examinadas a partir de um enfoque teórico-metodológico, socioecológico, estruturalista e experimental-individualista. Recentemente, modelos explicativos multidimensionais, que visam conciliar o hiato entre o determinismo estruturalista e o individualismo metodológico, vêm ganhando maior relevância (Sampson, 2012).

Essa vertente se norteia no conceito efeito-território (neighborhood effects), definido como as desvantagens estruturais que impactam na mobilidade socioeconômica (abrangendo os determinantes renda, ocupação e nível de educação) e nas condições de vida (englobando as variáveis saúde, padrões de sociabilidade, entre outras) do indivíduo em função da sua inserção em determinados contextos sociorresidenciais (Wilson, 1987). Enquanto existe consenso com respeito ao impacto negativo da segregação racial e econômica nas condições de vida dos moradores dos guetos socioespacialmente isolados, no que tange a seu acesso ao mercado de trabalho, assim como aos serviços urbanos, existe um maior dissenso com respeito às constelações urbanas marcadas pela proximidade geográfica entre grupos socialmente distantes (Small, 2004).

Conforme Sassen (1999), a interdependência funcional de grupos localizados no espectro oposto da estratificação social manifestar-se-ia particularmente nas regiões urbanas fronteiriças entre, por um lado, os guetos abrigando grupos étnico-raciais minoritários com um baixo perfil econômico e, por outro lado, os prédios involucrados em processos de gentrificação. A autora assevera que essa proximidade geográfica entre os grupos socialmente distantes favorece as articulações pelo viés empregatício.

Entretanto, Reich (1991) argumenta que a vida dentro dos condomínios fechados da classe média e alta assume maior totalidade para seus moradores à medida que estes crescentemente integram as funções de socialização e de trabalho. Como consequência, diminuem as necessidades e as oportunidades de se relacionar com pessoas extralocais, excetuando-se as relações empregatícias. Em decorrência das estruturas de segregação residencial, o contexto local de guetos e bairros pobres arrisca também se tornar mais "totalizante" para sua população em termos de interações sociais, com a diferença que esses locais crescentemente perdem sua função para os moradores dos bairros vizinhos.

Deslocando o enfoque para o contexto urbano latino-americano, cabe ressaltar que a organização dualista centro-periferia em termos de distribuição espacial das classes sociais, característica intrínseca à estrutura socioespacial das metrópoles estadunidenses, nunca se comprovou na integralidade do espaço urbano: tanto nas áreas centrais, quanto, recentemente, nas regiões mais periféricas das grandes metrópoles, surgiam constelações espaciais marcadas pela proximidade entre bairros pobres e os condomínios fechados das classes média e alta (Roberts, 2005). 
Recentemente, observa-se um crescente interesse em examinar as articulações funcionais entre os grupos socialmente distantes nessas constelações espaciais (Andrade e Silveira, 2013; Sabatini e Salcedo, 2007). Nesse sentido, pretende-se contribuir com o panorama dos estudos já realizados no Rio de Janeiro (Ribeiro et al., 2010), São Paulo (Marques, 2010) e Belo Horizonte (Andrade e Silveira, 2013) através de uma pesquisa qualitativa conduzida em uma cidade localizada fora do eixo economicamente mais dinâmico do Sudeste.

Salvador representa um estudo de caso interessante, nomeadamente por dois motivos: por um lado, existe uma expressiva proporção de pessoas precariamente inseridas no mercado laboral informal através do microempreendedorismo e do ramo de serviços pessoais de baixa produtividade. Por outro lado, as constelações de proximidade geográfica entre grupos socialmente distantes apresentam uma forte contingência histórica dentro da trajetória de expansão urbana da cidade, considerando-se que estas se produziam em um primeiro momento nas porções centrais da cidade, em um segundo momento no novo vetor de expansão da classe média-alta da Orla Atlântica Norte e, como fenômeno mais recente, em áreas mais periféricas (Carvalho e Pereira, 2014). Considerando esses fatores, pressupõe-se uma forte relevância do setor dos serviços pessoais e de baixa produtividade atendendo à demanda das classes média que permitiu absorver o excedente de mão de obra não qualificada, excluída do mercado laboral formal.

Os três bairros populares, Calabar, Vale das Pedrinhas e Bate Facho, que servem de recorte empírico desta pesquisa, inserem-se na Orla Atlântica, uma região economicamente dinâmica que começou a ser intensivamente ocupada pelas camadas média e alta desde a década de 1950. Excetuando-se o Vale das Pedrinhas, que forma parte de um conjunto de quatro bairros pobres contíguos, integrando a Região do Nordeste de Amaralina (RNA), trata-se de enclaves pobres que apresentam reduzidas dimensões territoriais e uma elevada incidência de crimes, particularmente no Vale das Pedrinhas.

Diante do exposto, visa-se a indagar se existem estruturas de oportunidades ${ }^{1}$ mais amplas para a integração socioeconômica das suas populações - dada a inserção dos bairros em um entorno geográfico no qual predominam os condomínios da classe média e alta com uma tradicionalmente forte demanda por serviços pessoais não qualificados (como faxineira, empregada doméstica, jardineiro, zelador, entre outros) - ou bem se essa relação de proximidade reforça as distâncias sociais. Para esse objetivo, examina-se o impacto do efeito-território na mobilidade socioeconômica e nas condições de vida dos moradores dos três bairros a partir de entrevistas semiestruturadas.

0 artigo compõe-se de quatro seções, além desta introdução e das considerações finais, e se estrutura de forma seguinte: a primeira seção delineia os principais desenvolvimentos dentro do debate acerca do efeito-território nos Estados Unidos e no Brasil. A segunda seção introduz a metodologia utilizada no estudo qualitativo, e a terceira seção apresenta os resultados auferidos na pesquisa qualitativa, os quais serão discutidos na quarta seção. 


\section{Examinando a dimensão espacial da pobreza a partir do conceito de efeito-território}

Atentando ao aumento das disparidades socioeconômicas e à crescente polarização socioespacial das grandes metrópoles no bojo do processo de desindustrialização e globalização, a sociologia estadunidense vem demonstrando, desde a década de 1990, um renovado interesse em indagar sobre as intercausalidades entre a concentração de determinadas desvantagens estruturais no bairro e a reprodução da pobreza a partir do efeito-território.

0 elemento-chave desse modelo explicativo remete ao conceito de isolamento social, definido como a ausência de contatos e de interações com indivíduos, grupos sociais e instituições da sociedade dominante (Wilson, 1987). Este leva em consideração a composição e os padrões de mobilização das redes sociais para acessar recursos (não) materiais e os processos de socialização a partir de determinados grupos de pares e modelos de referência social (Graif, Gladfelter e Matthews, 2014; Small e Newman, 2001). Nesse sentido, o conceito fundamenta-se nas premissas da sociologia econômica, que considera crucial a operacionalização do capital social, imbuído de relações interpessoais e institucionais, para a integração socioeconômica do indivíduo.

Aprofundando essas reflexões, Briggs (2003) assevera que as estruturas de redes que comportam um maior grau de homofilia ${ }^{2}$ e localismo 3 podem criar obstáculos à mobilidade socioeconômica do indivíduo na medida em que os vínculos sociais se constituem preponderantemente no âmago das esferas de sociabilidade primárias (a família, as amizades e a vizinhança), com escassos contatos extralocais.

0 autor remete à estreiteza das redes de sociabilidade, formadas principalmente por bonding ties, tecidos entre indivíduos pobres inseridos em contextos de vizinhança de composição social homogênea, considerando que isto contribui para a solidariedade e reciprocidade entre membros íntimos de uma rede, que podem ser mobilizados dentro de estratégias de sobrevivência a curto prazo. Em contrapartida, estudos empíricos assinalam a ausência de bridging ties em contextos de pobreza e segregação, ou seja, de redes sociais internamente mais diversificadas e territorialmente dispersas, com capacidade de alavancar a mobilidade econômica do indivíduo (Briggs, 2003; Tigges, Browne e Green, 1998).

Sampson (2012), abstraindo-se do enfoque analítico nos padrões de sociabilidade do indivíduo, procurou demonstrar que o impacto do efeito-território se vê atenuado pela capacidade de controle social informal da comunidade. Ao mesmo tempo, a erosão da collective efficacy ${ }^{\natural}$ favoreceria a infiltração de estruturas criminosas na sua organização social.

A discussão controvertida em torno do efeito-território tem impulsionado a elaboração de estratégias de dessegregação, como o programa Moving to Opportunity for Fair Housing (MTO), que visa ampliar as oportunidades de integração socioeconômica de famílias afro-americanas e pobres através do seu deslocamento seletivo para bairros da classe média com uma proporção menor de grupos minoritários étnico-raciais. Contudo, os resultados auferidos no quadro desse programa não evidenciaram melhorias substanciais na mobilidade 
socioeconômica das famílias relocadas; entretanto, efeitos positivos foram registrados nos indicadores percepção de segurança e saúde física/mental (Briggs, Popkin e Goering, 2010).

$A$ recepção do conceito de efeito-território ocorreu no Brasil a partir das revisões críticas de Small e Newman (2001). Enquanto existe um reconhecimento unânime do impacto negativo da concentração de desvantagens estruturais nas condições de vida e na mobilidade socioeconômica de indivíduos pobres habitando os bairros segregados localizados nas regiões periféricas das grandes metrópoles (Bógus e Pasternak, 2015; Carvalho e Pereira, 2014; Ribeiro et al., 2010), observa-se um maior dissenso referente à questão de se a proximidade espacial a bairros da classe média e alta amplia as estruturas de oportunidades para a população pobre.

Segundo Andrade e Silveira (2013), a proximidade aos condomínios fechados de um bairro pobre em Belo Horizonte proporciona uma ampla gama de ofertas de emprego aos moradores da favela Aglomerado da Serra, em comparação aos bairros periféricos inseridos em contextos de vizinhança homogeneamente pobres. A comparação do grau de inserção de moradores de favelas e não favelas no mercado de trabalho formal no Rio de Janeiro sinaliza a significante desvantagem em termos de rendimento médio acometendo o primeiro grupo, como mostram Ribeiro e Lago (1999), em função de mecanismos que transformam 0 estigma territorial em práticas discriminatórias no mercado de trabalho.

Fora do contexto das pesquisas brasileiras, existe uma série de contribuições empíricas que investigam as relações de imbricação funcional entre grupos socialmente distantes vivendo em proximidade geográfica em Santiago de Chile. Sabatini e Salcedo (2007) e Salcedo e Torres (2004), analisando o impacto da construção de condomínios fechados da classe média e alta nos bairros periféricos da capital chilena, concordam em enfatizar as maiores estruturas de oportunidades em termos de integração empregatícia para a população pobre. Ademais, assinalam as outras "externalidades positivas", como a construção de supermercados na região que empregam a população pobre.

Contudo, estudos mais recentes, conduzidos por Ruiz-Tagle (2016) no bairro periférico de la Florida, Santiago, demonstram que as chances de ser empregado dentro dos condomínios da classe média e alta se veem prejudicadas pela discriminação territorial da população moradora desse local. Em consequência, os funcionários são preponderantemente recrutados de outros bairros mais distantes que sofrem menos estigmas territoriais, fato que anula os benefícios de proximidade geográfica.

Convém ressaltar que nesses três estudos conduzidos em Santiago, Chile, trata-se de uma situação de "convivência" entre grupos socialmente distantes que difere essencialmente dos casos analisados no Brasil e do recorte empírico desta pesquisa. No caso chileno, os condomínios fechados inserem-se literalmente no meio dos bairros pobres localizados na região periférica de Santiago, dinâmica que, segundo Sabatini e Salcedo (2007) e Salcedo e Torres (2004), produziu a dispersão das camadas baixas no espaço. Similar ao contexto estadunidense, os estudos analisando esses desdobramentos espaciais recentes objetivam instigar uma discussão mais ampla em torno da eficiência das políticas de dessegregação 
para a redução das desigualdades socioeconômicas e para a integração social das populações pobres.

Entretanto, no Brasil, os condomínios fechados constituíram-se em bairros autônomos, localizados na adjacência das favelas, e, frequentemente, são separados fisicamente por muros e grades, pelo ambiente construído (avenidas, linhas de ferro e de metrô, represas, etc.) ou por barreiras naturais (parques públicos, rios, morros, etc.). Outrossim, o enfoque dos estudos brasileiros centra-se nas favelas e nos bairros populares inseridos nos interstícios das regiões mais centrais da cidade; trata-se, na sua grande maioria, de configurações espaciais de proximidade geográfica entre grupos socialmente distantes já consolidados.

Estudos sobre o efeito-escola norteiam-se pelas contribuições estadunidenses que versam sobre as consequências negativas advindas da socialização a partir de determinados grupos de pares e modelos de referência social (Small e Newman, 2001), gerando expectativas e comportamentos positivos ou negativos vis-à-vis a escola que podem interferir em uma futura integração no mercado de trabalho formal (Ribeiro e Kaztman, 2008).

Kaztman e Retamoso (2006) observam um enfraquecimento da capacidade de transmissão de modelos de referências da classe média e das possibilidades de troca de experiências dos alunos em Montevidéu, em decorrência da bifurcação entre o sistema de educação público e privado. No caso do Rio de Janeiro, a proximidade geográfica entre grupos socioeconomicamente distantes do tipo favela/bairro de classe alta incrementa as chances de atraso escolar de crianças e jovens pobres, dadas as distâncias em termos de padrões de consumo e condições de vida materiais e o desenvolvimento de modelos antagônicos aos padrões de desempenho das classes média e alta (Ribeiro et al., 2010).

Enfatizando a importância da análise das redes sociais para a compreensão dos efeitos da segregação territorial sobre a pobreza em distintos bairros de São Paulo, Marques (2010) constata que as redes mais locais e primárias impactam negativamente no rendimento médio do indivíduo, enquanto uma sociabilidade territorialmente mais diversificada, com maior proporção de vínculos formados no quadro de organizações de cunho associativista e religioso, incrementa a probabilidade de integração no mercado laboral formal.

Embora admitindo que inexistam laços entre indivíduos transcendendo a própria classe, 0 autor não adere à tese do isolamento social da classe baixa postulada por Wilson (1987), mas atribui, às redes primárias, a capacidade de intermediação a recursos e serviços que permitam a obtenção de auxílios sociais e maiores rendimentos, inclusive, no mercado laboral formal. Contrariando os resultados auferidos por pesquisadores dos Estados Unidos, Marques (2010) ressalta que, em certos casos, a segregação residencial torna a sociabilidade territorialmente mais dispersa e diversificada.

Em um estudo mais recente, que compara a estrutura das redes sociais de indivíduos pobres residindo em bairros segregados de São Paulo e Salvador, Marques, Castello e Bichir (2012) chegam a conclusões similares e destacam a baixa variabilidade entre os dois contextos urbanos analisados, ainda que se comprove um maior grau de localismo na capital baiana.

Andrade e Silveira (2013), focalizando as trocas de sociabilidade entre grupos 
socialmente distantes, revelam a persistência das distâncias sociais em decorrência do acesso hierarquizado por classe social ao sistema educacional e aos espaços de lazer. Já, para Almeida e d'Andrea (2004), a população do bairro da classe alta do Morumbi (São Paulo) engaja-se no combate à pobreza e violência na favela vizinha, Paraisópolis, através de redes filantrópico-assistencialistas e por meio de apoio financeiro a creches, escolas técnicas, postos de saúde e projetos socioculturais. Hita e Gledhill (2009) chegam a conclusões similares, a partir da análise das articulações entre os moradores do bairro popular Bairro de Paz, localizado na região periférica de Salvador, e seu entorno geográfico, composto majoritariamente por condomínios fechados da classe média e alta.

Outro grupo de pesquisadores destaca os problemas da integração social em contextos de vizinhança entre grupos socialmente distantes que decorrem da estigmatização dos moradores de baixa renda (Andrade e Silveira, 2013; Ruiz-Tagle, 2016). Ribeiro (2008) traz à baila reflexões sobre as tensões sociais originadas pela dominação simbólica dos moradores do Leblon (Rio de Janeiro), como recurso para "proteger seus capitais reificados no território de possíveis ameaças de desvalorização decorrentes da proximidade espacial com outros grupos" (p. 18), vis-à-vis os vizinhos do territorialmente estigmatizado conjunto habitacional da Cruzada de São Sebastião.

Esses resultados são largamente corroborados por Ruiz-Tagle (2016): a chegada dos condomínios fechados da classe média e alta não alavancou o diálogo entre os grupos socialmente distantes, dado o acesso segmentado às escolas, à infraestrutura comercial local e aos espaços de lazer. Práticas de distinção social que se produzem nos espaços públicos compartilhados inviabilizam a articulação entre os grupos socialmente distantes, e a população pobre sofre de uma série de discriminações nas suas trajetórias cotidianas.

Convém destacar que a apropriação do conceito de efeito-território no contexto urbano brasileiro ocorre ainda de forma desagregada, e a maioria dos estudos aqui revisados enfatiza um ou dois aspectos relevantes. Nesse sentido, pretende-se contribuir ao debate em curso a partir de uma pesquisa que examina tanto aspectos atinentes ao acesso ao mercado de trabalho e aos serviços urbanos, quanto os padrões de sociabilidade, às formas de organização coletiva e à percepção do indivíduo acerca da sua vulnerabilidade social, conforme será demonstrado a seguir.

\section{Considerações metodológicas}

Em nosso estudo qualitativo, recorre-se ao arcabouço metodológico proposto pelo sociólogo alemão Häußermann (2003), que examina o efeito-território a partir das três dimensões material, social e simbólica. A dimensão material remete à localização geográfica do bairro em relação ao conjunto da cidade, abordando-se aspectos atinentes ao acesso do indivíduo ao mercado de trabalho, ao transporte público, a serviços urbanos e à infraestrutura comercial, social e cultural. Já a dimensão social abrange três componentes analíticos, quais sejam: a estrutura das redes sociais, a capacidade de collective efficacy e a influência de grupos de pares e modelos de referência locais em processos de socialização. 
Na dimensão simbólica, indaga-se acerca do impacto negativo provocado na mobilidade socioeconômica e nas condições de vida do indivíduo através da estigmatização territorial. Esta pode produzir diversas experiências de desintegração nos indivíduos e causar disrupções na sua autoestima; analisam-se, nesse sentido, as distintas formas de discriminação territorial, por exemplo, na hora de procurar um emprego ou na abordagem pela polícia.

Convém ressaltar que, em nossa pesquisa, enfatiza-se a forte relevância das redes sociais e institucionais na sua função de mitigar as situações de vulnerabilidade social. Essa premissa se fundamenta no argumento que, em virtude das deficiências de capacidade de absorção de grandes contingentes populacionais no mercado de trabalho formal e da ausência de um sistema de bem-estar social, a reprodução social das camadas baixas nos países latino-americanos esteve historicamente assentada na combinação entre mercado (informal), família, comunidade - e crescentemente as igrejas (evangélicas) (González De La Rocha et al., 2004; Kaztman e Filgueira, 2006).

Para o nosso objetivo, examina-se, em primeiro lugar, a participação do indivíduo nas diferentes esferas de sociabilidade no intuito de avaliar se este recorre nas suas interações cotidianas preponderantemente a vínculos sociais locais ou extralocais (Marques, 2010). Em nosso caso, distingue-se entre, por um lado, as esferas de sociabilidade primárias, quais sejam: a família, os amigos e os vizinhos, caraterizadas por um alto grau de homofilia e localismo; e, por outro lado, as esferas de sociabilidade secundárias, quais sejam: trabalho, estudos, associações (não-)leigas e lazer. Pressupõe-se que estas últimas ampliam o espectro e a diversidade dos vínculos sociais dos entrevistados, com importantes implicações para sua integração econômica.

Em segundo lugar, busca-se explorar se e como os entrevistados encontram oportunidades empregatícias tanto no seu próprio bairro quando nos condomínios vizinhos da classe média alta, examinando-se particularmente a importância de pessoas-chave dentro de determinadas redes sociais que possam intermediar vagas de emprego para os trabalhos desempenhados nos condomínios. Em terceiro lugar, procura-se examinar se os habitantes recorrem preponderantemente a bonding ties ou bridging ties para obter suporte (não)material.

A abordagem da importância dos grupos de pares e modelos de referência social em processos de socialização justifica-se em atendimento à hipótese central de Wilson (1987) do isolamento social. Nesse sentido, pressupõe-se um enfraquecimento da legitimidade dos canais "formais" de mobilidade social, como a frequência da escola, a obediência das normas legais vigentes, o respeito da vida dos outros moradores, etc., atentando-se, particularmente, à influência de jovens e adultos afiliados ao tráfico de drogas nos locais analisados.

A integração do conceito de collective efficacy dentro do nosso arcabouço metodológico é de particular interesse, dado que se pressupõe um impacto significativo da criminalidade e da violência na organização social da comunidade e nas condições de vida do indivíduo. Nesse sentido, recorre-se ao índice composto de collective efficacy, elaborado por Sampson (2012), para avaliar a capacidade do indivíduo de controle social informal.

0 primeiro indicador sintético "índice de expectativas compartilhadas de controle 
social" será avaliado a partir de uma tipologia composta por cinco itens na escala Likert, ${ }^{5}$ nesse caso, os habitantes foram solicitados a se posicionar acerca da sua disposição de se engajar em ações coletivas na vizinhança a partir da simulação de situações distintas, sobre crianças e acontecimentos na proximidade.

Os outros indicadores são: 1) "índice de coesão/confiança social", que investiga o grau de desconfiança que prevalece entre os vizinhos de um dado bairro: os entrevistados foram solicitados a se pronunciar acerca de situações como ajudar os vizinhos e outras; e 2 "índice de violência observada na vizinhança", que se baseia em questões como registrar/presenciar briga violenta entre vizinhos e outras situações. Finalmente, para medir o quarto indicador, "índice de vitimização pessoal", o entrevistado foi solicitado a responder a questões relacionadas a ocorrência de crime contra ele ou sua família.

A pesquisa foi conduzida em três diferentes bairros populares de Salvador, considerados como exemplos paradigmáticos para a configuração espacial de proximidade geográfica entre grupos socialmente distantes. Na Figura 1, apresenta-se a localização dos três bairros populares dentro do município de Salvador: 0 Calabar insere-se na região da Orla Atlântica Sul, no sudoeste da capital baiana; enquanto os bairros Vale das Pedrinhas e Bate Facho se inserem na Orla Atlântica Norte, seguindo o vetor de expansão dos bairros da classe média e alta emergindo na década de 1970.

A escolha desses locais se justifica a partir da pressuposição de uma certa variabilidade em termos do que se denomina, neste trabalho, "grau de imbricação funcional" da população dos três bairros na cidade, vis-à-vis seu entorno geográfico, pressupondo-se uma diferenciação hierárquica obediente à ordem descendente seguinte: Calabar - Vale das Pedrinhas - Bate Facho, que corresponde a sua distância geográfica ante as centralidades (em termos de oportunidades empregatícias e de oferta de serviços urbanos) antigas de Salvador de uso funcional "misto" do espaço, quais sejam: o centro histórico, Comércio, Barra, Lapa, Barroquinha, etc.

Nessas regiões se supõe haver maior convergência física entre os grupos socialmente distantes nas estruturas públicas de uso coletivo em comparação ao vetor de expansão da classe média e alta, que emergiu na década de 1970 (no caso: Vale das Pedrinhas e Bate Facho), marcado pela primazia do uso residencial do espaço em que as áreas de lazer com potencial de promover as trocas de sociabilidade entre os grupos socialmente distantes revelam um caráter altamente elitizado.

Para o objetivo do nosso estudo, foram realizadas 90 entrevistas semiestruturadas, no período de maio a novembro de 2017, com aproximadamente meia hora de duração, em distintos locais do bairro e em diferentes horários, abordando-se as pessoas aleatoriamente na rua. 0 interlocutor foi solicitado, em primeiro lugar, a fornecer alguns dados acerca de renda familiar, status ocupacional, nível de escolaridade, idade, gênero, estado civil e número de filhos, que serviam de variáveis de controle. Em segundo lugar, aplicou-se um questionário semiaberto nos três bairros, que, para maiores esclarecimentos, se encontra o anexo a este artigo. De forma complementar, foram realizadas diversas entrevistas com os líderes comunitários nos três bairros, com o objetivo de obter informações sobre a organização socioinstitucional e a trajetória histórica do bairro. 
Figura 1- Localização dos três bairros estudados no município de Salvador e distribuição das classes sociais a partir do critério de renda

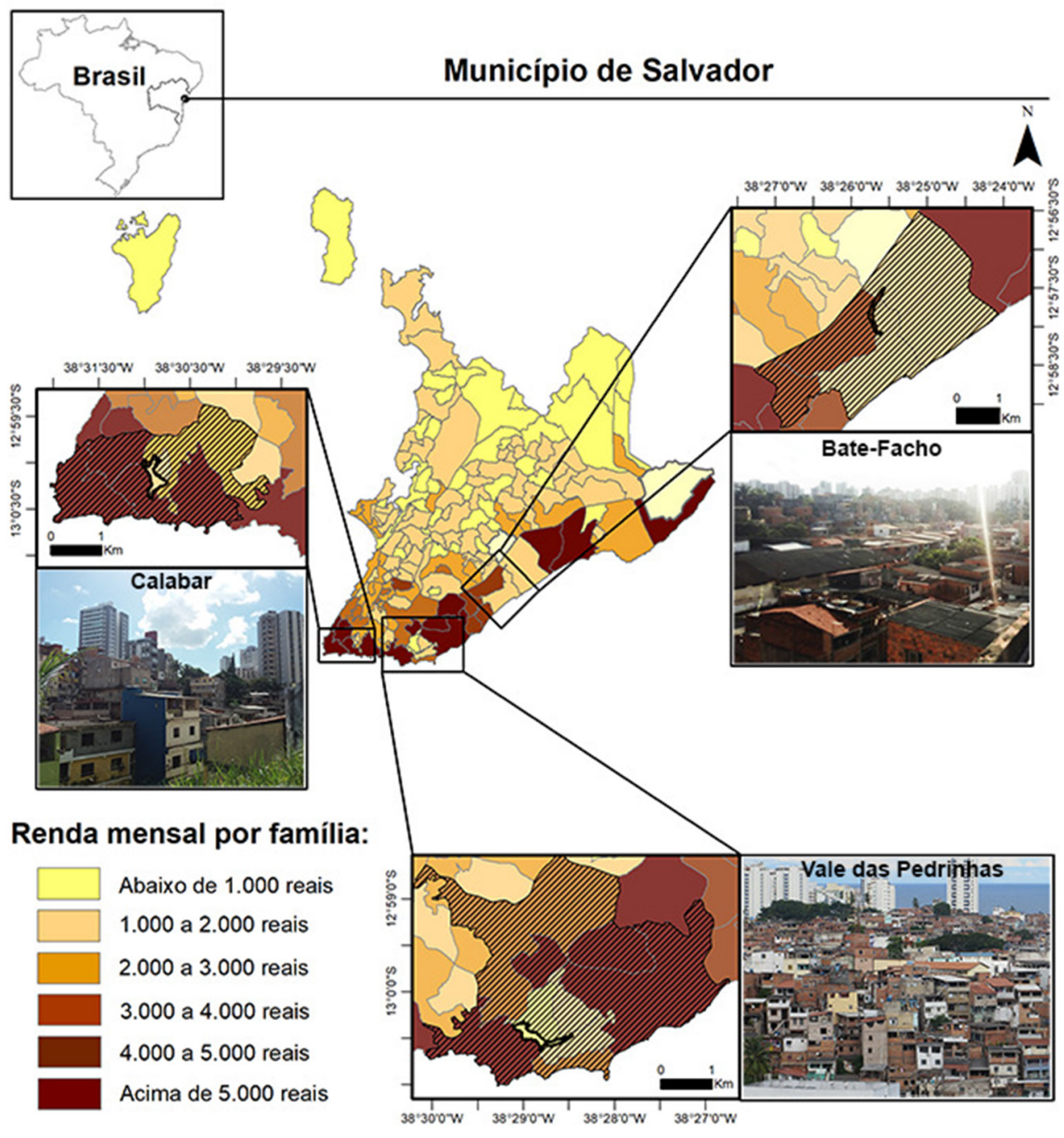

Observação: 0 mapa foi elaborado através do software ArcGIS (versão 10), a partir do arquivo vetorial (formato shapefile) dos bairros de Salvador, feito pela Companhia de Desenvolvimento Urbano do Estado da Bahia (Conder); a distribuição dos grupos sociais a partir do critério de renda média familiar baseia-se nos dados divulgados pela Conder (2016) e, respectivamente, no caso do Bate Facho, pelo Programa das Nações Unidas pelo Desenvolvimento (Pnud). Utiliza-se aqui a renda média familiar como critério exclusivo de identificação geográfica das três localidades.

Fonte: elaboração própria. 
A amostra integra pessoas de diferentes perfis socioeconômicos, observando-se, no entanto, uma variabilidade relativamente baixa dentro do grupo dos entrevistados no que tange ao nível de renda (entre meio e um e meio salário mínimo de renda familiar), grau de escolaridade (nível médio incompleto até completo) e status ocupacional (aproximadamente um terço dos entrevistados se autodeclarou desempregado). Para evitar qualquer viés na seleção da amostra, o perfil sociodemográfico das pessoas entrevistadas abrange todas as faixas etárias, entre 16 e 65 anos, que correspondem a distintos ciclos de socialização e de aquisição dos recursos necessários à reprodução social.

\section{Examinando o efeito-território em três bairros populares de Salvador}

\section{Calabar}

0 bairro de Calabar surgiu na década de 1950, quando grupos populacionais empobrecidos oriundos majoritariamente do interior do estado vieram se instalar nos terrenos devolutos, pertencentes à Santa Casa de Misericórdia. Aproximadamente 1.700 domicílios particulares permanentes (6.484 habitantes), dos quais $89,37 \%$ são classificados como aglomerados subnormais, distribuem-se ao longo de 5,4 quilômetros de extensão. ${ }^{6}$ Com 38.726 hab./ $\mathrm{km}^{2}$, a localidade acusa uma das taxas de densidade demográfica mais elevadas da cidade 0 rendimento familiar médio no Calabar totalizava 1.029 reais, contrastando com os bairros vizinhos, Barra (6.585 reais), Ondina (7.615 reais) e Graça (7.772 reais). A proporção de chefes de família de domicílios particulares permanentes sem renda elevava-se a 17,9\% em 2010, enquanto a taxa de desemprego somava $14,76 \%$. Da população do Calabar, $88,89 \%$ autodeclarou-se negro ou pardo, proporção que atinge $37,82 \%$ na Graça, 44,28\% na Barra e 50,80\% na Ondina.

Em relação ao nível de escolaridade, cabe ressaltar que apenas 3,68\% dos chefes de família possuem um diploma do ensino superior, enquanto essa proporção atinge 37,88\% na Ondina, 42,86\% na Graça e 46,02\% na Barra. Aproximadamente 35\% das mulheres chefes de família com crianças não tinham completado o ensino fundamental, 32,30\% da população encontrava-se em situação de vulnerabilidade à pobreza e 25,30\% dos habitantes maiores de idade não haviam completado 0 ensino fundamental e se encontravam em ocupação informal.

Com respeito à dimensão material, cabe assinalar as vantagens locacionais do Calabar beneficiando uma parte das pessoas entrevistadas que decorrem da proximidade às estruturas de oportunidades empregatícias encontradas no seu entorno geográfico, principalmente nos condomínios dos bairros Barra, Graça, Federação e Ondina. Outro grande polo de emprego é representado pelas praias do Porto da Barra, Morro do Cristo e Farol da Barra, todas localizadas a uma distância de uma caminhada de quinze a vinte minutos. Nesse caso, os entrevistados enfatizam a importância desses locais para a auferição de renda, através da venda de lanches e bebidas nas praias ou no passeio da Orla, ao mesmo tempo que os pontos estratégicos na entrada 
dos condomínios são utilizados para a venda informal de frutas, legumes e lanches.

Sem levar em consideração o vínculo empregatício, essa relação de proximidade a um entorno geográfico onde predominam as camadas média e alta também se torna relevante no acesso a infraestrutura e equipamento urbano dos moradores do Calabar, uma vez que oferece serviços de maior qualidade, particularmente em termos de saúde e educação. Prevalece uma avaliação positiva dos entrevistados acerca da vitalidade da infraestrutura social e cultural no Calabar, fato que promove um alto grau de articulação entre seus moradores e que fortalece a identidade territorial com o bairro, principalmente a partir do engajamento de algumas instituições-chave em favor do bem coletivo da comunidade, como as igrejas neoprotestantes, a biblioteca comunitária e a associação dos moradores. Os entrevistados não visualizam os espaços públicos de lazer e recreação, quais sejam a avenida Centenário, o Shopping Barra e as praias espalhadas pela Barra e Ondina, como pontos de encontro com potencial trocas de sociabilidade.

Concernente à dimensão social, chama a atenção o fato de que não se confirma um confinamento dos habitantes ao contexto social local. Pelo contrário, discerne-se uma expressiva orientação das relações sociais para os bairros vizinhos, o que confere maior grau de dispersão territorial e diversidade interna às suas redes sociais. Essa conectividade com pessoas não residentes é corroborada, preponderantemente, no caso das pessoas que possuem um maior raio de atuação em função dos seus percursos diários casa-trabalho, casa-estudos e casa-lazer.
0 acesso a informações sobre vagas de emprego se vê beneficiado pela intermediação através de pessoas-chave já trabalhando nos condomínios vizinhos. Em virtude da alta proporção do mercado informal no conjunto das atividades profissionais exercidas pelos entrevistados, as esferas primárias de sociabilidade, quais sejam: família, amigos e vizinhança, ganham uma relevância particular no Calabar, já que são precisamente as pessoas mais íntimas dentro da rede de contatos dos moradores que usufruem das indicações de trabalho. Registra-se um enfraquecimento da vizinhança como estrutura de reciprocidade e de suporte intracomunitário; em contrapartida, ganha mais relevância a igreja na hora de promover suporte (não)material, como pequenos empréstimos, doação de alimentos e conselhos emocionais.

Incumbe-se um papel-chave à Base Comunitária de Segurança (BCS), implementada em 2011, no que refere ao restabelecimento da segurança pública do bairro. Anteriormente, o local era considerado, por seus moradores e pela mídia, como bastião do tráfico de drogas, aterrorizando a população local; no entanto, desde 2011, os entrevistados declaram ter recuperado a confiança nas pessoas, fato que teria facilitado a locomoção e a articulação entre as duas divisões territoriais do bairro, Camarão e Bomba. A supervisão de comportamentos desviantes pelos próprios moradores assim como a atuação preventiva da biblioteca comunitária, da BCS e da escola aberta, através do oferecimento de uma ampla gama de atividades supervisionadas, fortalecem a capacidade de controle social informal.

Observa-se, ao investigar a influência de grupos de pares e modelos de referência, tanto dentro da vizinhança quanto no âmbito da 
escola, uma nítida distinção entre um "antes" e um "depois" da implantação da BCS dentro da estrutura narrativa dos entrevistados. Fica evidente que o impacto de modelos de referência negativos e grupos delinquentes em processos de socialização nas crianças e adolescentes não possui uma grande relevância posterior à atuação da BCS no Calabar.

Dentro da dimensão simbólica, a maioria confirma a prevalência de mecanismos de discriminação territorial; contudo, poucos entrevistados relatam que esse fator constranja efetivamente sua integração no mercado laboral formal ou informal. Chama a atenção o fato de que a imagem atribuída pelo exterior não corresponde à realidade vivenciada dentro do bairro, segundo a percepção de virtualmente todos os entrevistados. Um dos logros principais da implantação da BCS no bairro consistiu na alteração da imagem da polícia como órgão público repressor que intervinha apenas em situações críticas para uma imagem segundo a qual os agentes que integram a BCS são visualizados como polícia de proximidade que, além do policiamento ostensivo, se esforçam a construir laços de confiança com a população residente com o objetivo de erradicar as estruturas criminosas no local.

\section{Vale das Pedrinhas}

A ocupação inicial da região que hoje forma o Vale das Pedrinhas foi propulsada por pescadores que se instalaram nas terras devolutas na segunda metade do século XIX em razão da proximidade à faixa litorânea da cidade. 0 bairro abriga uma população total de 5.162 pessoas - distribuída por 1633 domicílios particulares permanentes, sendo 248 destes qualificados como aglomerados subnormais e alcançou uma densidade demográfica bruta de 33.105 hab. $/ \mathrm{km}^{2}$. 0 rendimento nominal médio dos chefes de família alcançou 1.292 reais em 2010, enquanto, na Amaralina, alcançou 3.592 reais; no Rio Vermelho, 6.282 reais; na Pituba, 7.513 reais; na Cidade Jardim/Candeal, 9.274 reais; e, no Horto Florestal, 11.312 reais. Da população, $84,75 \%$ se declarou como negro ou pardo enquanto essa proporção atinge $60,56 \%$ na Amaralina, $54,85 \%$ no Rio Vermelho e 43,13\% na Pituba.

Quanto ao nível de escolaridade, observa-se que apenas $0,52 \%$ dos chefes de família possui educação superior completa, enquanto no Rio Vermelho esta proporção atinge 32,44\%; na Pituba, 33,81\% ; e, no Horto Florestal, 51,34\%. A taxa de mortalidade infantil somava 12,70 por mil crianças nascidas. Aproximadamente $27,27 \%$ das mulheres chefes de família com filho menor não tinham completado o ensino fundamental. Em 2010, 24,86\% da população estava em situação de vulnerabilidade à pobreza e $21,58 \%$ de pessoas de 18 anos ou mais estavam sem ensino fundamental completo e trabalhava no mercado laboral informal.

Com respeito à dimensão material, convém remeter às vantagens locacionais do Vale das Pedrinhas beneficiando, contudo, apenas um número reduzido dos moradores. Os entrevistados relatam que o declínio nas oportunidades empregatícias do setor de serviços pessoais desempenhados nesses locais se atrela à conjuntura econômica desfavorável afetando a classe média, às alterações na legislação de trabalho da empregada doméstica e à estigmatização territorial do Vale das Pedrinhas. As porções beirando a avenida Juracy Magalhães Júnior, a principal entrada do bairro, oferecem 
menos possibilidades de venda informal, dada a predominância da função residencial no Horto Florestal e Candeal e do alto grau de proteção dos condomínios fechados. Abstraindo-se das opções de lazer, distribuídas preponderantemente ao longo da praia da Amaralina, os hospitais da rede privada margeando a avenida Juracy Magalhães Júnior assim como as instituições de ensino privadas estão fora do alcance financeiro dos entrevistados.

Prevalece uma percepção negativa com respeito à disposição de infraestrutura social e cultural no bairro: o vácuo de organizações comunitárias e associações filantrópicas, suscetíveis de fortalecer a solidariedade e a coesão intracomunitária, é parcialmente recompensado pela atuação das igrejas evangélicas. Não existem espaços públicos e de lazer que possam ser compartilhados pelos moradores do Vale das Pedrinhas e os moradores dos condomínios do Horto Florestal e Candeal.

Concernente à dimensão social, chama a atenção que as estruturas das redes sociais dos entrevistados transcendem um maior grau de localismo, com uma nítida concentração nas esferas primárias de sociabilidade, quais sejam: família e amigos. Mesmo sendo controladas pelas variáveis status ocupacional, renda, nível de educação, ciclo de vida e sexo, é possível identificar estruturas de redes similares que testemunham de um recuo para as esferas de sociabilidade mais íntimas.

Um dos fatores que limita o contato com pessoas extralocais atrela-se às dificuldades de locomoção dos seus habitantes principalmente durante a noite para os bairros vizinhos, 0 que deixa as pessoas mais confinadas em casa. A predominância do contexto social local na constituição das redes sociais dos entrevistados também remete ao fato de que, levando-se em consideração o conjunto dos bairros populares integrando a RNA, trata-se de uma região com maior autonomia funcional em termos de acesso a mercado de trabalho (informal), escolas, hospitais e estabelecimentos comerciais, o que torna o contato com pessoas extralocais menos indispensável.

É oportuno destacar que a função dos vínculos sociais como intermediadores para um emprego nos condomínios vizinhos desempenha um papel secundário. Registra-se uma certa resistência de recomendar e indicar pessoas do seu círculo íntimo de parentes e amizades, alegando-se o medo que tais pessoas possam prejudicam a própria relação de confiança com o patrão, devido ao risco de furtos cometidos nos condomínios.

Dado o alto grau de localismo das redes e a predominância de um perfil socioeconômico baixo dos integrantes das redes sociais analisadas, existem dificuldades de obter informações extralocais sobre vagas de emprego e sobre a disponibilidade de recursos (não)materiais. Segundo os relatos dos entrevistados, a vizinhança como estrutura de suporte nunca desempenhou um papel de destaque para os moradores. Essa situação ainda teria se agravado em períodos recentes como resultado da atuação de grupos ligadas ao tráfico de drogas no bairro e na RNA.

Observa-se uma significante desestabilização da organização social da comunidade em decorrência da criminalidade, que reduz a disposição dos entrevistados de zelar de forma voluntária pela ordem social na comunidade. Predomina o sentimento de insegurança dos entrevistados, fato que constrange suas rotinas diárias e prejudica as formas de 
articulação tanto dentro do bairro quanto entre as quatro localidades.

Subsequentemente, reforça-se o sentimento de impunidade com respeito às infrações menores contra as normas sociais coletivamente estabelecidas pela comunidade. Essa dinâmica se torna particularmente evidente na hora de intervir quando acontece uma briga em frente da casa do entrevistado, uma vez que que a maioria dos entrevistados declarou que não ajudaria na resolução do conflito. Essa tendência de não intromissão se vê agravada por uma falta de confiança na polícia que, segundo a percepção dos entrevistados, não intervém de forma pacificadora em delitos menores. Carece também de referências sociais positivas proporcionadas por uma organização comunitária ou por instituição filantrópica. Tanto no ambiente das quatro escolas locais quanto no contexto do próprio bairro, constata-se uma forte influência de grupos de pares locais vinculados ao tráfico de drogas.

Em relação à dimensão simbólica, observa-se a prevalência de estigmas territoriais advindos da associação do bairro e do conjunto de bairros que integram a RNA, com uma imagem dominada pelo tráfico de drogas. Os entrevistados apontam distintas formas de discriminação, como na busca de um emprego ou na abordagem institucional enviesada pela polícia, que se veem retroalimentadas pelas reportagens midiáticas.

\section{Bate Facho}

0 Bate Facho, localizado na proximidade do bairro da classe média Imbui, constituiu-se em vila de pescadores nas primeiras décadas do século XX por pessoas oriundas de diferentes partes da Bahia. Em 2010, a população chegou a aproximadamente 5.000 pessoas (21.198 hab./km²), que se distribuíam por 1.399 domicílios. 0 rendimento nominal médio do chefe de família alcançava 822 reais, em comparação com 1.709 reais na Boca do Rio, 1.885 reais no Pituaçu, 4.352 reais no Imbui e 8.641 reais no bairro de Piatã.

0 Bate Facho comporta uma alta proporção de habitantes que se autodeclara de cor ou raça parda ou negra, totalizando, nesse caso, $84,75 \%$. Ao mesmo tempo, essa taxa alcança $63,09 \%$ no Imbui e $51,49 \%$ no bairro de Piatã. Concernente ao nível escolar, apenas 1,9\% dos chefe de família concluiu o ensino superior, proporção que chega a $32,45 \%$, no Imbui, e $43,05 \%$ no bairro de Piatã. A taxa de mortalidade infantil alcançou 30,20 por mil crianças nascidas em 2010, e a proporção de mães chefes de família sem ensino fundamental e com filho menor de idade somava 50,29\%. Da população, $54,72 \%$ era considerada vulnerável à pobreza, e $42,61 \%$ das pessoas com até 18 anos não tinham completado o ensino fundamental e estavam trabalhando no setor informal.

Quanto à dimensão material, convém ressaltar que os entrevistados experimentam uma série de dificuldades de encontrar um emprego, o que mostra que os condomínios vizinhos não promovem maiores estruturas de oportunidades empregatícias. Abstraindo-se das possibilidades de venda informal de produtos em pontos estratégicos localizados nos arredores do bairro, o entorno geográfico não mitiga a situação de vulnerabilidade social dos moradores.

Verificou-se uma série de desvantagens estruturais que se concentram à escala do bairro e que impactam negativamente nas 
condições de vida dos entrevistados, como a ausência de instituições associativo-culturais, creches, escolas, postos de saúde e áreas de lazer, obrigando-os a se deslocar para os bairros vizinhos. Essa situação se vê agravada pela precariedade da estrutura habitacional-viária do bairro e pela alta exposição dos moradores a riscos ambientais, como enchentes e alagamentos. Carece de espaços compartilhados frequentados pelos moradores do Bate Facho e pelos moradores dos condomínios do Imbui com a exceção da Praça do Imbui e de um parque de lazer para crianças, localizados na área limítrofe com o Imbui, local onde se ostentam distintas práticas de distinção social, criando obstáculos a uma articulação maior entre os grupos socialmente distantes.

$\mathrm{Na}$ dimensão social, observa-se que as redes sociais se constituem preponderantemente no âmago das esferas primárias, com um expressivo grau de localismo e homofilia, mesmo sendo controladas pelas variáveis status ocupacional, renda, grau de escolaridade, sexo e idade. Esse confinamento ao contexto social local dificulta o acesso a informações extralocais sobre vagas de emprego, uma tendência que se vê agravada pela alta incidência de desemprego no Bate Facho. Enquanto a vitalidade do sistema de suporte e reciprocidade primário fortalece os laços vicinais, particularmente em situações emergenciais, a expressiva orientação ao contexto social local estreita o horizonte dos contatos.

Uma tendência de declínio da função da vizinhança como estrutura de suporte (não) material também pode ser comprovada, ainda que em dimensões menos significativas do que no Vale das Pedrinhas. No Bate Facho, esse processo foi acompanhado por uma afiliação maior dos entrevistados às distintas igrejas evangélicas espalhadas pelo bairro, que promovem vários tipos de suporte (não)material aos membros da congregação. As redes sociais coesas tecidas entre os vizinhos, parentes e amigos locais não logram intermediar questões de empregos locais ou recursos (não)materiais, dada a insuficiência de oportunidades de trabalho no bairro; as altas taxas de desemprego que desassociam os moradores do mercado de trabalho como plataforma para indicar pessoas da sua rede; e os elevados níveis de vulnerabilidade à pobreza conjugados com uma escassez de recursos materiais.

Todavia, existe um alto grau de disposição em intervir de forma controladora e corretiva no comportamento de crianças e adolescentes, tanto em situações de ociosidade quanto de desrespeito às pessoas idosas. Prevalece um elevado grau de coesão e solidariedade no bairro, fato que também deve ser atrelado à menor presença de grupos criminosos afiliados ao tráfico de drogas. Dessa forma, a segurança pública não se vê comprometida e se mantém estável a relação de confiança entre os vizinhos e os corresidentes. Da mesma maneira, não se atesta a influência de grupos de pares e modelos de referência vinculados ao tráfico de drogas no bairro.

Dentro da dimensão simbólica, destaca-se a interferência de uma imagem negativa reproduzida pela mídia que constrange os entrevistados na busca de emprego e nas articulações com pessoas não residentes do bairro. $A$ estigmatização territorial também dificulta 0 acesso a alguns serviços privados, como táxi ou transporte privado alternativo, que não consideram seguro entrar no Bate Facho principalmente durante no período da noite. 


\section{Discussão}

Tendo em vista os resultados auferidos neste estudo comparativo, salienta-se que a proximidade geográfica aos condomínios beneficia a integração econômica dos moradores no setor dos serviços pessoais, conforme já destacado por outros pesquisadores (Andrade e Silveira, 2013; Hita e Gledhill, 2009; Sabatini e Salcedo, 2007). É oportuno ressalvar que essa integração econômica ocorre a partir de formas de emprego que podem ser consideradas como não qualificadas e de baixa remuneração - e que, na sua grande maioria, não dão direito à carteira assinada -, fato que não viabiliza uma mobilidade econômica ascendente da população dos três bairros no longo prazo.

Ademais, a relação de imbricação funcional pelo viés empregatício não deve ser interpretada como resultado "invariável" e "automático" da proximidade geográfica entre grupos socialmente distantes: como denominador comum, todos os três bairros usufruíam da forte demanda que emergia, em uma primeira fase, na construção civil dos prédios de condomínios da classe média e alta e, em uma segunda fase, a partir dos serviços pessoais desempenhados dentro dos condomínios.

Para essas duas fases, comprova-se a validade do argumento de Sassen (1999), asseverando que os grupos de pessoas incluídos e excluídos da economia formal se encontram em uma relação de imbricação funcional. A ênfase nessas relações "simbióticas" evoca uma imagem de uma sociedade mais polarizada, mas, ao mesmo tempo, funcionalmente interdependente.

Contudo, registra-se um declínio em termos de demanda, particularmente no caso do Bate Facho, que contrasta com um período anterior marcado pela forte demanda em serviços pessoais nos condomínios do Imbui. Entretanto, no Vale das Pedrinhas, a articulação entre os grupos socialmente distantes pelo viés empregatício viu-se constrangida pela associação do local com o tráfico de drogas. Já, no Calabar, a população continua usufruindo das amplas possibilidades de mercantilização de distintos produtos em espaços públicos ou em frente aos condomínios.

0 estudo também corroborou que as estruturas de segmentação social hierarquizam 0 acesso aos serviços urbanos, particularmente evidentes no acesso desigual a escolas e hospitais, com exceção do Calabar, onde se evidencia um maior grau de uso compartilhado dessas estruturas. Em todos os bairros, o acesso aos espaços públicos de lazer, localizados no seu entorno, acusa um alto grau de hierarquização por classe social, o que se manifesta nas práticas de distinção social já investigadas por Ribeiro (2008).

0 estudo aponta um expressivo confinamento das relações sociais ao contexto local no caso do Vale das Pedrinhas e no Bate Facho. Entretanto, no Calabar, há maior orientação extralocal dos entrevistados em virtude das amplas oportunidades de participação socioeconômica no seu entorno, confirmando-se as observações de Marques (2010) acerca da baixa incidência dos fatores pobreza e segregação nos padrões de sociabilidade do indivíduo. Já, no caso do Vale das Pedrinhas, as considerações de Wilson (1987), acerca dos efeitos negativos do isolamento social para a integração socioeconômica do indivíduo, tornam-se relevantes, dado que a população jovem frequenta preponderantemente as escolas locais e recruta suas 
amizades majoritariamente no bairro, o que aumenta o risco de exposição a grupos de pares e modelos de referência social nocivos para sua futura integração socioeconômica.

Nos três bairros analisados, articulações entre grupos socialmente distantes extrapolando o vínculo empregatício raramente acontecem, corroborando as considerações de Ruiz-Tagle (2016) de que a integração da população pobre unilateralmente pelo viés econômico - ainda que beneficiando alguns poucos entrevistados no nosso caso - não promove sua integração social vis-à-vis seu entorno geográfico.

No Vale das Pedrinhas, a atuação de grupos criminosos em conjunção com a desconfiança nos vizinhos e órgãos públicos minam a capacidade de collective efficacy da comunidade; enquanto, no Calabar, a implementação da BCS e o alto grau de mobilização coletiva fortalecem essa capacidade. 0 fator criminalidade interfere nos processos de socialização, particularmente dos segmentos mais jovens, tanto dentro do ambiente da escola quanto na própria vizinhança no caso do Vale das Pedrinhas.

Na dimensão simbólica, evidenciam-se as maiores convergências entre os três bairros. Salienta-se a persistência de uma forte estigmatização territorial dos entrevistados por pessoas não residentes, que constrange seu processo de integração no mercado laboral, 0 acesso a determinados serviços e as possibilidades de interação com não residentes. Convém acrescentar que, no caso do Vale das Pedrinhas, observam-se distintas formas de discriminação nas abordagens policiais.

Destaca-se o papel proeminente da mídia televisiva em veicular uma imagem enviesada desses lugares habitados por uma população potencialmente perigosa. Similarmente ao contexto urbano estadunidense (Sampson, 2012; Small, 2004; Wilson, 1987), a falta de contato entre os grupos socialmente distantes dificulta a desconstrução dos preconceitos reproduzidos pela mídia. Ressalta-se que, apesar da prevalência dos estigmas territoriais, virtualmente todos os entrevistados se dizem satisfeitos de morar nesses locais.

A forte identificação territorial dos moradores com seu lugar de residência não se fundamenta unilateralmente no maior acesso às estruturas de oportunidades: 0 alto grau de satisfação em morar nesses bairros atrela-se principalmente à qualidade da vida social dos moradores, que se assenta em vínculos íntimos e coesos, tecidos nas esferas primárias de sociabilidade e que, em casos mais isolados, se construíram no ambiente das estruturas institucionais e das igrejas evangélicas. Essa característica contrasta com o alto grau de insatisfação dos moradores dos guetos estadunidenses, conforme documentado nos estudos de Wilson (1987) e Sampson (2012).

Diante da variabilidade dos resultados auferidos nos três bairros, destacam-se dois condicionantes principais que incidem sobre a capacidade dos entrevistados de apropriar-se das estruturas de oportunidades nos bairros vizinhos: por um lado, a capacidade de os espaços públicos compartilhados viabilizarem trocas mercantilistas e interações entre os grupos socialmente distantes, e, por outro lado, a interferência de estruturas criminosas na organização social da comunidade. Contrastando com 0 contexto estadunidense, incumbe uma função proeminente ao mercado informal no sentido de permitir maior integração econômica do 
indivíduo em uma região predominantemente habitada pelas classes média e alta.

No caso do Calabar, trata-se de um bairro inserido na zona de expansão mais antiga das classes média e alta de Salvador, que se encontra em proximidade aos principais polos do mercado de trabalho, tanto formal quanto informal. Observa-se uma elevada participação socioeconômica dos entrevistados nos espaços públicos da sua circunferência, ainda que persistam as práticas de distinção na apropriação do espaço público pelas camadas altas.

Já o Vale das Pedrinhas pode ser visualizado como bairro integrado à RNA, complexo de quatro bairros empobrecidos que sofrem de uma forte influência do tráfico de drogas. $A$ inserção socioeconômica da sua população na Orla Atlântica Norte esbarra com uma série de desafios decorrentes das poucas possibilidades de participação socioeconômica nos espaços públicos, tanto para o lazer quanto para a mercantilização de produtos. Esse fator decorre da predominância da função do uso de solo classificado como residencial nos bairros mais próximos da classe alta, quais sejam: o Horto Florestal e o Candeal, assim como da forte presença de dispositivos de segurança e monitoramento nesses condomínios fechados.

No Bate Facho, evidenciam-se as mesmas dificuldades de participação nos bairros vizinhos, quanto ao acesso ao mercado laboral informal e aos serviços urbanos. No bairro vizinho Imbui, predomina claramente a função residencial, abstraindo-se das partes geográficas, margeando a avenida Paralela.

No que tange às relações e articulações entre os grupos socialmente distantes que foram examinadas no nosso estudo, salientam-se quatro fatores: (1) as maiores oportunidades empregatícias, particularmente nos condomínios, mas também no setor de venda informal de produtos em pontos estratégicos; (2) a persistência das estruturas de segmentação social em termos de acesso aos serviços urbanos; (3) a evitação social do "outro", abstraindo-se das articulações empregatícias; e (4) a imagem negativa dos três bairros como bastiões do tráfico de drogas que abrigam uma população potencialmente perigosa.

\section{Considerações finais}

Este estudo, enfocando os momentos reprodutores da pobreza urbana a partir da sua dimensão espacial, demonstrou que o contexto sociorresidencial impacta na mobilidade socioeconômica e nas condições de vida dos 90 entrevistados através de uma série de processos e mecanismos, operados na escala do bairro, que foi identificada nas dimensões material, social e simbólica.

Em consideração da significante variabilidade entre os três bairros, pleiteia-se por uma perspectiva condicional vis-à-vis a análise do impacto do efeito-território, que se distancia da concepção universalista do gueto como instituição, defendida pela leitura estruturalista da pobreza de Wilson (1987). Essa perspectiva condicional busca desvendar os mecanismos pelos quais operam o efeito-território em distintos bairros sem, no entanto, inferir uma generalização desses efeitos (Small, 2004).

Por exemplo, as estruturas do crime organizado interferem, a princípio, nos três bairros e podem ser consideradas como um dos principais mecanismos operacionais de um 
efeito-território. No entanto, seu impacto se vê condicionado pela prevalência de recursos institucionais (Calabar), pela presença de redes densas e coesas de vizinhança (Bate Facho) ou também pela ausência destes dois elementos atenuantes (Vale das Pedrinhas).

A aproximação condicional ao efeito-território prevê que bairros que comportem uma população de perfil socioeconômico baixo não são internamente homogêneos; do mesmo modo, os indivíduos não se veem afetados igualmente pelo contexto sociorresidencial no qual eles se inserem. No entanto, a associação causal entre os fatores atrelados à escala do bairro e os fatores que se reportam ao próprio indivíduo não pode ser considerada como arbitrária, senão se assenta em determinadas estruturas similares.

Em que pese a grande relevância da dimensão espacial da pobreza para modelos explicativos, examinando-se os mecanismos de reprodução das desigualdades sociais nas metrópoles brasileiras, é imperativo inserir os processos a partir dos quais se opera o efeito-território nos três bairros nas dimensões macrossociais e macroeconômicas. 0 estudo demonstrou que a mobilidade socioeconômica dos entrevistados assim como suas possibilidades de acessar recursos (não)materiais e de mobilizar suas redes sociais para mitigar situações de vulnerabilidade se veem estreitamente condicionadas pelas estruturas de oportunidades promovidas pelo mercado de trabalho e pelas políticas sociais.

A grande importância que se incumbe ao mercado informal em Salvador deve ser levada em consideração como fator explicativo para a análise dos padrões de mobilização dos vínculos sociais dos entrevistados, dado que são precisamente as redes tecidas nas esferas primárias de sociabilidade que incidem positivamente sobre suas probabilidades de integração econômica. Excetuando-se o caso do Vale das Pedrinhas - com respeito à influência dos grupos de pares afiliados ao tráfico de drogas -, o conceito de isolamento social cunhado no contexto urbano estadunidense possui um valor explicativo secundário, já que não se evidencia uma dissociação dos entrevistados vis-à-vis o sistema de valores e os modelos de referência da sociedade dominante.

Acrescenta-se, a esses dois fatores, a necessidade de atentar às transformações sociais ocorridas nas últimas três décadas, como a alteração do modelo da família nuclear e a reorganização dos sistemas de suporte e reciprocidade no caso das camadas baixas, ressaltando-se a crescente importância das igrejas evangélicas na promoção de recursos (não)materiais. Um quarto fator remete às alterações na organização socioespacial da cidade em apreço, destacando-se a relevância da análise dos mecanismos de segmentação social - no caso brasileiro, a bifurcação em um sistema público e privado de educação e saúde que impede as articulações entre os grupos socialmente distantes - e das estruturas de segregação residencial.

Este último fator se torna pertinente para nosso estudo, tendo em vista a historicamente consolidada configuração de proximidade geográfica entre grupos socialmente distantes em Salvador que se produziu em distintas regiões da cidade. Contrastando com os contextos urbanos analisados em Santiago de Chile (Ruiz-Tagle, 2016) e com o contexto 
urbano estadunidense (Sassen, 1999; Small, 2004), trata-se tendencialmente mais de uma dinâmica historicamente contingente na trajetória de crescimento urbano da cidade do que de um fenômeno recente da gentrificação. Nesse sentido, nossa pesquisa contribuiu para a análise das transformações das relações de imbricação funcional entre os grupos socialmente distantes ao longo do tempo e identificou os fatores locais que condicionam o acesso às estruturas de oportunidades, quais sejam: as possibilidades de participação socioeconômica nos espaços públicos compartilhados e a infiltração do tráfico de drogas na organização social da comunidade.

Diante dessas considerações, convém reconhecer que o confinamento da questão social à dimensão espacial tende a ofuscar a visão para as três principais causas da reprodução das iniquidades sociais nas metrópoles brasileiras, quais sejam: a persistência das disparidades socioeconômicas - coadunando com a linha de raça -, as estruturas de segmentação social e a retração do Estado em relação às políticas sociais de alcance universal no setor de saúde e educação. Partindo dessas reflexões, as estratégias de combate às desigualdades sociais deveriam abstrair do seu enfoque local.

Todavia, estudos qualitativos investigando o impacto do efeito-território nas condições de vida do indivíduo podem contribuir substancialmente para a elaboração de políticas de intervenção urbana à medida que atentam tanto aos potenciais endógenos da comunidade, em termos de organização socioinstitucional, quanto às deficiências, em termos de infraestrutura, equipamento urbano e segurança pública. Por se tratar de um fenômeno que tende a deteriorar-se sob uma conjuntura econômica desfavorável, considerando-se o congelamento das despesas sociais em vários setores-chave, como saúde, educação e segurança pública, a abordagem do impacto da concentração de desvantagens estruturais à base do conceito de efeito-território pode ganhar maior relevância dentro do panorama da sociologia brasileira e dentro da agenda das políticas urbanas.

Contudo, o aprofundamento dessa temática exige a integração de uma avaliação quantitativa do efeito-território à base de dados fornecidos pelo censo de 2000 e 2010 . Essa técnica teria a vantagem de retraçar as transformações na ordem do perfil sociodemográfico da população, a partir da seleção de distintos períodos de medição, e iria permitir responder à questão central sobre se poderia ser comprovada a permanência da concentração de desvantagens na escala do bairro.

A partir da combinação de métodos quantitativo-estatísticos e qualitativos, poder-se-ia estabelecer, em um primeiro momento, uma série de relações causais entre 0 impacto de determinadas desvantagens concentradas na escala do bairro, por exemplo, entre um baixo nível de renda familiar e altas taxas de reprovação escolar, para, em um segundo momento, explorar essas intercausalidades de uma forma mais pormenorizada à base da condução de entrevistas e de observações de campo. 


\section{[I] https://orcid.org/0000-0002-4455-6452}

Universidade Federal da Bahia. Faculdade de Ciências Sociais. Salvador, BA/Brasil.

stephantreuke@hotmail.de

\section{Notas}

(1) Neste trabalho, as "estruturas de oportunidades" definem-se tanto em termos de oportunidades empregatícias quanto em termos de acesso dos indivíduos entrevistados a serviços urbanos de alta qualidade, concentrados nos bairros adjacentes aos três locais investigados.

(2) O conceito de homofilia remete ao princípio que a convergência em determinados atributos, como idade, gênero, nível educativo, raça/etnia, religião, classe ou status social, etc., tende a produzir maior probabilidade de se inter-relacionar e de concordar em específicas opiniões e práticas similares.

(3) O conceito localismo reporta-se à probabilidade de uma dada rede do indivíduo se compor preponderantemente de membros habitando o mesmo local.

(4) Conforme Sampson (2012), o conceito collective efficacy combina a coesão social e a confiança mútua com a expectativa compartilhada de controle social informal, conceito compreendido neste contexto como a maneira em que os vizinhos podem contar com o apoio de outrem para manter a ordem pública, monitorar e vigiar as crianças e adolescentes conforme práticas, normas e sanções coletivamente estabelecidas.

(5) A escala Likert será utilizada dentro do roteiro de questões aplicado nas entrevistas, com o objetivo de verificar o nível de concordância do entrevistado com determinadas afirmações.

(6) Os dados estatísticos apresentados a seguir na caracterização do perfil econômico e sociodemográfico da população dos três bairros provêm do Sistema de Informação Municipal de Salvador (SIM), do PNUD e da Conder e se reportam ao Censo de 2010.

\section{Referências}

ALMEIDA, R. e D'ANDREA, T. (2004). Pobreza e Redes Sociais em uma Favela Paulistana. Novos Estudos Cebrap. São Paulo, v. 28, pp. 94-106.

ANDRADE, L. T. e SILVEIRA, L. S. (2013). Efeito-território. Explorações em torno de um conceito sociológico. Civitas. Porto Alegre, v. 13, n. 2, pp. 381-402.

BÓGUS, L. M. M. e PASTERNAK, S. (orgs.) (2015). São Paulo: transformações na ordem urbana. Rio de Janeiro, Letra Capital. 
BRIGGS, X. de S. (2003). Bridging Networks, Social Capital, and Racial Segregation in America. John F. Kennedy School of Government Faculty Research Working Paper Series Paper RWP02-011, Harvard University.

BRIGGS, X. de S.; POPKIN, S. J. e GOERING, J. (2010). Moving to Opportunity. The Story of an American Experiment to Fight Ghetto Poverty. Nova York, Oxford University Press.

CARVALHO, I. M. M. de e PEREIRA, G. C. (orgs.) (2014). Salvador: transformações na ordem urbana: metrópoles: território, coesão social e governança democrática. Rio de Janeiro, Letra Capital.

CONDER; INFORMS (2016). Painel de informações: dados socioeconômicos do município de Salvador por bairros e prefeituras-bairro. Salvador, Secretaria de Desenvolvimento Urbano e Sistema de Informações Geográficas Urbanas do Estado da Bahia.

GONZÁLEZ DE LA ROCHA, M. et al. (2004). From the marginality of the 1960s to the "New Poverty" of Today. Latin American Research Review. Pittsburgh, v. 39, n. 1, pp. 183-203.

GRAIF, C.; GLADFELTER, A. S. e MATTHEWS, S. A. (2014). Urban poverty and neighborhood effects on crime: incorporating spatial and network perspectives. Sociology Compass, v. 8/9, pp. 1140-1155.

HITA, M. G. e GLEDHILL, J. (2009). Anthropologies of the Urban Periphery: Salvador, Bahia. BWPI Working Papers 97. Manchester, Brooks World Poverty Institute.

HÄUßERMANN, H. (2003). Armut in der Großstadt. Die Stadtstruktur verstärkt soziale Ungleichheit. Informationen zur Raumentwicklung. Berlin, v. 3/4, pp. 143-157.

KAZTMAN, R. e FILGUEIRA, F. (2006). Las Normas como Bien Público y como Bien Privado: Reflexiones en las Fronteras del Enfoque AVEO. Montevidéu, Universidad Católica del Uruguay.

KAZTMAN, R. e RETAMOSO, A. (2006). Segregación Residencial en Montevideo: Desafíos para la Equidad Educativa. Santiago de Chile, Comisión Económica para América Latina y el Caribe.

MARQUES, E. C. de L. (2010). Redes sociais, segregação e pobreza. São Paulo, Editora Unesp.

MARQUES, E. C. L.; CASTELLO, G. e BICHIR, R. M. (2012). Redes pessoais e vulnerabilidade social em São Paulo e Salvador. Revista USP. São Paulo, v. 92, pp. 32-45.

PNUD - Programa das Nações Unidas pelo Desenvolvimento (2018). Atlas do Desenvolvimento Humano do Brasil. Disponível em: <http://www.atlasbrasil.org.br/2013/>. Acesso em: 30 nov 2018.

REICH, R. (1991). The Work of Nations. Nova York, Random House.

RIBEIRO, L. C. de Q. (2008). Proximidade territorial e distância social: reflexões sobre o efeito de lugar a partir de um enclave urbano. VeraCidade. Salvador, v. 3, n. 3, pp. 1-21.

RIBEIRO, L. C. de Q. e LAGO, L. C. do (1999). O espaço social das grandes metrópoles brasileiras: Rio de Janeiro, São Paulo e Belo Horizonte. Cadernos Metrópole. São Paulo, n. 4, pp. 9-32.

RIBEIRO, L. C. de Q. e KAZTMAN, R. (orgs.). (2008). A cidade contra a escola? Segregação Urbana e Desigualdades educacionais em grandes cidades da América Latina. Rio de Janeiro, Letra Capital.

RIBEIRO, L. C. de Q.; KOSLINSKI, M. C.; ALVES, F. e LASMAR, C. (orgs.) (2010). Desigualdades urbanas, desigualdades escolares. Rio de Janeiro, Letra Capital/Observatório das Metrópoles.

ROBERTS, B. R. (2005). Globalization and Latin American Cities. International Journal of Urban and Regional Research. Hoboken, N.J., v. 29, n. 1, pp. 110-123. 
RUIZ-TAGLE, J. (2016). La persistencia de la segregación y la desigualdad en barrios socialmente diversos: un estudio de caso en la Florida, Santiago. EURE. Santiago de Chile, v. 42, n. 125, pp. 81-108.

SABATINI, F. e SALCEDO, R. (2007). Gated Communities and the Poor in Santiago, Chile: Functional and Symbolic Integration in a Context of Aggressive Capitalist Colonization of Lower-Class Areas. Housing Policy Debate. Newbury Park, v. 18, n. 3, pp. 577-606.

SALCEDO, R. e TORRES, A. (2004). Gated Communities in Santiago: Wall or Frontier? International Journal of Urban and Regional Research. Hoboken, v. 28, n. 1, pp. 27-44.

SAMPSON, R. J. (2012). Great American City. Chicago and the Enduring Neighborhood Effect. Chicago, The University of Chicago Press.

SASSEN, S. (1999). "Service Employment Regimes and the New Inequality". In: MINGIONE, E. (org.). Urban poverty and the underclass: a reader. Malden, Blackwell Publishers.

SIM (Sistema de Informação Municipal de Salvador) (2018). Disponível em: <http://www.sim.salvador. ba.gov.br/>. Acesso em: 30 nov 2018.

SMALL, M. L. (2004). Villa Victoria. The Transformation of Social Capital in a Boston Barrio. Chicago, The University of Chicago Press.

SMALL, M. L. e NEWMAN, K. (2001). Urban Poverty After The Truly Disadvantaged: The Rediscovery of the Family, the Neighborhood, and Culture. Annual Review of Sociology. Palo Alto, v. 27, pp. 23-45.

TIGGES, L. M.; BROWNE, I. e GREEN, G. P. (1998). Social Isolation of the Urban Poor: Race, Class, and Neighborhood Effects on Social Resources. The Sociological Quarterly. Hoboken, v. 39, n. 1, pp. 53-77.

WILSON, W. J. (1987). The declining significance of race: black and changing american institutions. Chicago, The University of Chicago Press.

Texto recebido em 31/out/2018

Texto aprovado em 27/nov/2018 